\title{
A VARIABILIDADE PLUVIOMÉTRICA NO CARIRI CEARENSE E A INFLUENCIA DAS TELECONEXÕES ENOS E ODP
}

\author{
Jéssica Ramires $^{\left({ }^{(a)}\right.}$, Núbia BerayArmond ${ }^{(\mathrm{b})}$, Carla Maciel Salgado ${ }^{(\mathrm{c})}$ \\ (a) Aluna do Programa de Pós-Graduação em Geografia, Universidade Federal Fluminense, jessicaramires@id.uff.br \\ (b) Profa. do Departamento de Geografia Física, Universidade do Estado do Rio de Janeiro, \\ nubiarmond@hotmail.com \\ (c) Profa. do Departamento de Geografia, Instituto de Geociências, Universidade Federal Fluminense, \\ carlasalgado@id.uff.br
}

Eixo: Climatologia em diferentes níveis escalares: mudanças e variabilidades

\begin{abstract}
Resumo
No Nordeste do Brasil, a regularidade da chuva é o principal fator que afeta a vida da população. A distribuição anual e interanual da precipitação neste e em outros locais do mundo é afetada por padrões de variabilidade, como El Niño - Oscilação Sul (ENOS) e Oscilação Decenal do Pacífico (ODP). A área de estudo deste artigo abrange as cidades do Crato, Jardim, Milagres e Brejo Santo, ao sul do Ceará, na área do Cariri Cearense, caracterizada por ser um enclave semi-úmido no meio da região semi-árida. O objetivo é analisar a variabilidade temporal da precipitação e buscar interações entre esta e a ODP e ENOS. Para tanto, foram utilizados dados da Agência Nacional de Águas (ANA), relacionados aos índices da ENOS e ODP disponibilizados pela NOAA e Universidade de Washington. Os resultados encontrados corroboram com a literatura, principalmente no que se refere à relação de background entre o ENOS e a ODP, bem como a influência destas teleconexões na variabilidade interanual das chuvas na área em estudo.
\end{abstract}

Palavras chave: ENOS, ODP, precipitação pluviométrica, Nordeste do Brasil, Cariri.

\section{Introdução}

O mito historicamente construído do Nordeste do Brasil (NEB) como um lugar miserável por ser seco (NIMER, 1989) ajuda a formar no imaginário coletivo que mais importa a quantidade das chuvas que sua regularidade. Porém, se sabe que as variabilidades sazonal, intra e interanual da precipitação exercem consequências mais acentuadas nas atividades sociais e econômicas que os totais anuais (MENDONÇA; DANNI-OLIVEIRA, 2007). Atrelado a isso, a situação latitudinal faz com que a chuva no NEB seja o elemento climático que mais caracteriza sua sazonalidade (BARROS e ZAVATTINI, 2009), compondo duas estações nas faixas equatorial e tropical: estação seca e estação chuvosa.

Sabe-se que a chuva é um dos elementos mais relevantes para o planejamento territorial a curto e longo prazo, e afeta de forma sensível grupos sociais dos mais variados, bem como instituições públicas, privadas e as dinâmicas da vida social de forma ampla. Logo, o estudo das teleconexões pode auxiliar no 
entendimento da dinâmica pluviométrica e consequentemente na organização das comunidades humanas. Ao considerar a Terra como um sistema, entende-se que suas diferentes partes são interdependentes, o que significa que continentes, oceanos e atmosfera estão em constante interação, e mutuamente, são influenciados pelo Sistema Solar (MOLION, 2005). Tendo em vista esses pressupostos, considera-se que os sistemas produtores de chuva (centros de ação, massas de ar, frentes e sistemas locais e regionais) são influenciados pelas teleconexões, que modulam a intensidade e o alcance de tais sistemas. As teleconexões são definidas como anomalias que, apesar de ocorrerem em uma localidade, influenciam outros locais do planeta devido à constituição da atmosfera como um fluido em constante interação com o oceano e os continentes (CAVALCANTI, et al. 2009).

Como um padrão de variabilidade, a Oscilação Decenal do Pacífico (ODP), assim como o El Niño Oscilação Sul (ENOS), possui fases quentes (positivas) e frias (negativas), porém seus ciclos são muito mais longos, ocorrendo de 20 a 30 anos, e de 50 a 70 anos. Em 1947, a ODP iniciou sua fase negativa, cujo término se deu em 1976, dando espaço para a fase positiva, que durou de 1977 a 1998. O início dos anos 2000 foram marcados por uma nova fase fria da ODP, que, segundo projeções, perdurará até pelo menos a segunda década do século XXI (MANTUA, 2002; MOLION, 2005).

A posição geográfica da região NEB, situada na faixa equatorial, mas estendendo-se até $15^{\circ}$ sul, faz com que a influência de centros de ações e sistemas atmosféricos em várias escalas, tais como complexos convectivos, linhas de instabilidade, e sistemas como Zona de Convergência do Atlântico Sul (ZCAS), Sistemas Frontais (SF), Zona de Convergência Intertropical (ZCIT), além dos fenômenos de escala local como brisa marítima e terrestre, entre outros, produzam os tipos de tempo da região, assim como a sazonalidade das estações seca e chuvosa (SIQUEIRA et al. 2006). No caso do NEB, o que caracteriza o verão é a presença da estação chuvosa, em parte causada pela ZCIT, sendo chamado popularmente de “inverno" pelos nordestinos (AB’SABER, 2003).

Para o NEB, o principal sistema produtor de chuva é a ZCIT, porém esta é influenciada por fenômenos atmosféricos e oceânicos que interferem em sua amplitude e na força dos ventos alísios. No caso, consideramos as influências das teleconexões El Niño - Oscilação Sul (ENOS) e Oscilação Decenal do Pacífico (ODP), fenômenos oceânico-atmosféricos que possuem a capacidade de modificar a Célula de Walker (CW), ou seja, a circulação longitudinal da atmosfera. A CW funciona em níveis, o que significa que funciona em diferentes escalas. Ao nível do mar, nas proximidades dos Arquipélagos do oceano Índico, se estabelece uma célula de alta pressão e, em contraposição, na costa do Peru, encontramos uma célula de baixa pressão. Esses ventos provenientes da alta pressão no oceano Índico, que ocorrem em alta troposfera, não descem apenas no Peru, mas também unem-se a Célula de Hadley $(\mathrm{CH})$, formando a 


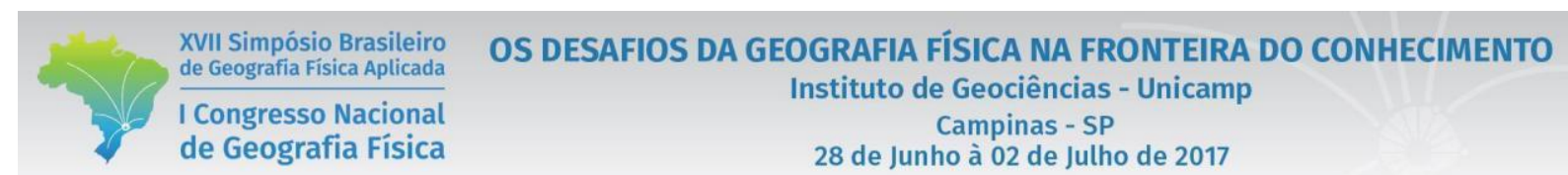

circulação de Hadley-Walker com a modulação da dinâmica do ASAS. Os ventos alísios do ASAS seguem para a América do Sul, promovendo a advecção de umidade oceânica para este continente. Nesta trajetória, que vai até a Cordilheiras dos Andes, acaba por formar um complexo conjunto de células de baixa pressão que atua de maneira contundente sobre a Floresta Amazônica. Tais ventos convectivos acabam por descer sobre o NEB, solidificando o ASAS, dificultando a migração da ZCIT para sul e agravando a ausência de chuvas sobre a região. Como o ENOS tem a capacidade de enfraquecer ou fortalecer os alísios através da modificação da $\mathrm{CW}$, este fenômeno também induz secas extremas ou chuvas mais intensas no NEB (SIQUEIRA, et al. 2006; IAG/USP, 2016).

A área estudada abrange os municípios do Crato, Jardim, Brejo Santo e Milagres, situadas no sul do estado do Ceará - CE e contornando a Chapada do Araripe (Figura 1). Ela representa uma importante barreira orográfica na região, pois chega a ultrapassar $900 \mathrm{~m}$ de altitude. A Região Sul do Ceará possui o diferencial da sua pluviosidade poder ser considerada elevada para clima semiárido, apesar de estar inserida no coração do Nordeste, onde a seca pode durar de sete a oito meses, ou mais (NIMER, 1989).

Tendo em vista a importância das teleconexões para a dinâmica climática local, o objetivo do trabalho é compreender como o ENOS e a ODP exercem influência sobre a variabilidade pluviométrica na Região do Cariri Cearense, que possui o clima caracterizado pelo IBGE (2002) como semi-úmido.

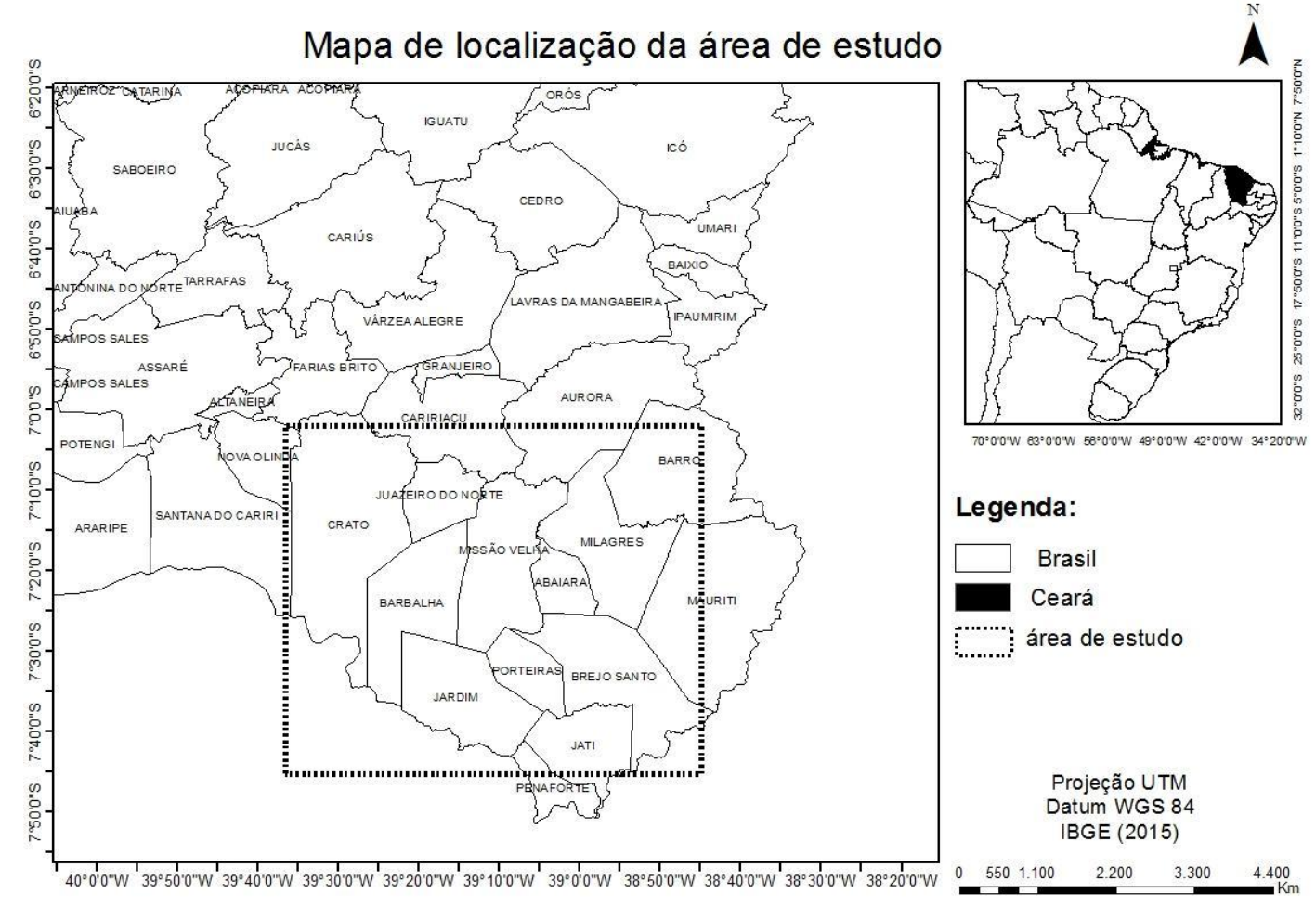

Figura 1 - Localização da área de estudo ao sul do Ceará.

Elaboração: Debora da Paz Gomes Brandão. 


\section{Procedimentos Metodológicos}

Foram coletados dados de postos pluviométricos localizados na região sul do Ceará, através do site da Agência Nacional de Águas (ANA), sendo utilizado o programa Hidro 1.2.1. Após a coleta dos arquivos, os dados, dispostos em arquivos .txt, foram convertidos em tabelas de extensão .xls do software Microsoft Excel, para manejo e aprimoramento dos dados.

Foram selecionados quatro postos (Quadro 1), utilizando os seguintes critérios: 1) de tempo de funcionamento dos mesmos - de 1910 a 2014; 2) mínimo de trinta anos de dados ininterruptos - com lacunas de, no máximo, cinco meses, e 3) estarem no máximo a $50 \mathrm{~km}$ de distância entre si. Apesar dos postos disporem de mais de cem anos de dados diários, devido à complexidade analítica que demandariam, optou-se por analisar apenas a série histórica de 1960 a 2013.

Para compreender a dinâmica climática local, foram coletados os dados de outros elementos climáticos da única estação meteorológica da região, operada pelo INMET e localizada em Barbalha, cidade circundada por Crato e Jardim. Apesar de constar, no BDMEP, que o início da estação de Barbalha foi em 1948, a estação conta com dados apenas a partir de 1983, com os quais foi possível montar um gráfico de elementos climáticos com vistas a analisá-los em sua dinâmica.

Na planilha eletrônica, os dados de chuva foram agrupados em totais mensais, sazonais e anuais.

Quadro 1 -Relação dos postos pluviométricos de Brejo Santo, Milagres, Crato e Jardim, e da estação meteorológica de Barbalha, analisados no presente estudo. Fonte: Agência Nacional de Águas (ANA) e Banco de Dados

Meteorológicos para Ensino e Pesquisa do Instituto Nacional de Meteorologia (BDMEP - INMET) .

\begin{tabular}{|c|c|c|c|c|c|c|c|c|c|}
\hline $\begin{array}{l}\text { Cóg. } \\
\text { Posto }\end{array}$ & Estado & $\begin{array}{l}\text { Nome } \\
\text { posto }\end{array}$ & Cidade & Latitude & Longitude & $\begin{array}{c}\text { Altitude } \\
\text { (m) }\end{array}$ & Responsável & Operadora & $\begin{array}{c}\text { Início/ } \\
\text { Fim }\end{array}$ \\
\hline 738006 & Ceará & $\begin{array}{l}\text { Brejo } \\
\text { Santo }\end{array}$ & $\begin{array}{l}\text { Brejo } \\
\text { Santo }\end{array}$ & $-07: 29: 28$ & $-038: 59: 00$ & 490 & FUNCEME & FUNCEME & $\begin{array}{l}1910 / \\
2014\end{array}$ \\
\hline 738008 & Ceará & Milagres & Milagres & $-07: 18: 00$ & $\begin{array}{l}-038: 56: 00 \\
\end{array}$ & 371 & FUNCEME & FUNCEME & $\begin{array}{l}1912 / \\
2014\end{array}$ \\
\hline 739006 & Ceará & Crato & Crato & $-07: 14: 00$ & $-039: 24: 00$ & 421 & FUNCEME & FUNCEME & $\begin{array}{l}1912 / \\
2014\end{array}$ \\
\hline 739038 & Ceará & Jardim & Jardim & $-07: 35: 00$ & $-039: 17: 00$ & 630 & FUNCEME & FUNCEME & $\begin{array}{l}1910 / \\
2014\end{array}$ \\
\hline 82784 & Ceará & Barbalha & Barbalha & $\begin{array}{l}-7: 31: 00 \\
\end{array}$ & $-39: 29: 00$ & 409 & $\begin{array}{l}\text { BDMEP - } \\
\text { INMET }\end{array}$ & $\begin{array}{c}\text { BDMEP - } \\
\text { INMET }\end{array}$ & $\begin{array}{l}1948 / \\
2016\end{array}$ \\
\hline
\end{tabular}

Os dados pluviométricos somados deram origem à Chuva Acumulada Anual (CHA), para então realizar uma comparação com os dados do ENOS e da ODP. Para tanto, foram feitas tabelas contendo os valores totais de precipitação de cada ano, a média de precipitação e o desvio padrão da série histórica para cada posto. Seguindo essa organização, foi feita uma segunda planilha para cada posto, para a realização da 
operação de padronização dos dados anuais de cada posto segundo o Índice Multivariado do ENOS (Multivariate ENSO Index - MEI) e o Índice da ODP (Pacific Decadal Oscillation Index - PDO). Os dados do MEI foram obtidos no site do Earth System Research Laboratory do National Oceanic and Atmospheric Administration (ESRL - NOAA), enquanto os dados da ODP foram obtidos no site do Joint Institute for the Study of the Atmosphere and Ocean (JISAO), da Universidade de Washington.

A padronização é uma operação realizada em planilha eletrônica, constituindo-se em uma função do software Microsoft Excel. Para realizá-la, é necessário a confecção de uma tabela contendo uma coluna com os totais anuais, uma célula com a média (função: =AVERAGE) pluviométrica de todos os anos e outra com o desvio padrão (função: =STDEV). Uma vez pronta, uma segunda tabela deve ser feita, realizando a padronização de cada ano, célula a célula, utilizando os valores da primeira tabela (função: =STANDARDIZE). Exemplo, a célula a ser preenchida com a padronização é a H4, que corresponde ao ano de 1960 da cidade de Brejo Santo. O total anual de 1960, a média da série histórica e o desvio padrão da cidade de Brejo Santo se encontram nas células B4, B58 e B59 respectivamente, a função encontrada na célula H4 será =STANDARDIZE(B4;B58;B59).

Com os dados organizados, foram produzidos gráficos comparativos entre a pluviosidade da região, o ENOS e a ODP. Tais gráficos possuem, no eixo vertical, o valor em porcentagem. Escolheu-se estruturar desta forma, uma vez que tratam-se da junção dos elementos padronizados (valores pluviométricos em mm e índices ENOS e ODP em ${ }^{\circ} \mathrm{C}$ ), para que não houvesse erro na elaboração dos gráficos.

\section{Resultados}

As características climáticas gerais da região do Cariri Cearense estão expressas na Figura 2, por meio de médias mensais de elementos climáticos considerando a série histórica de 1983-2013. Pode-se observar o aumento significativo da pressão atmosférica em conjunto com os ventos de sudeste, entre junho e novembro. Esta situação é característica da atuação do ASAS nos meses de inverno e primavera no hemisfério austral. Em consequência, ocorre menos precipitação, há a diminuição da nebulosidade e da umidade relativa, assim como o aumento da amplitude térmica. Já nos meses de verão e outono (entre final de dezembro e maio), com a chegada ao ápice meridional da ZCIT, observa-se a diminuição da pressão atmosférica, o predomínio de ventos de nordeste e leste, o aumento da nebulosidade e umidade relativa, e a diminuição das temperaturas máximas assim como da amplitude térmica. 


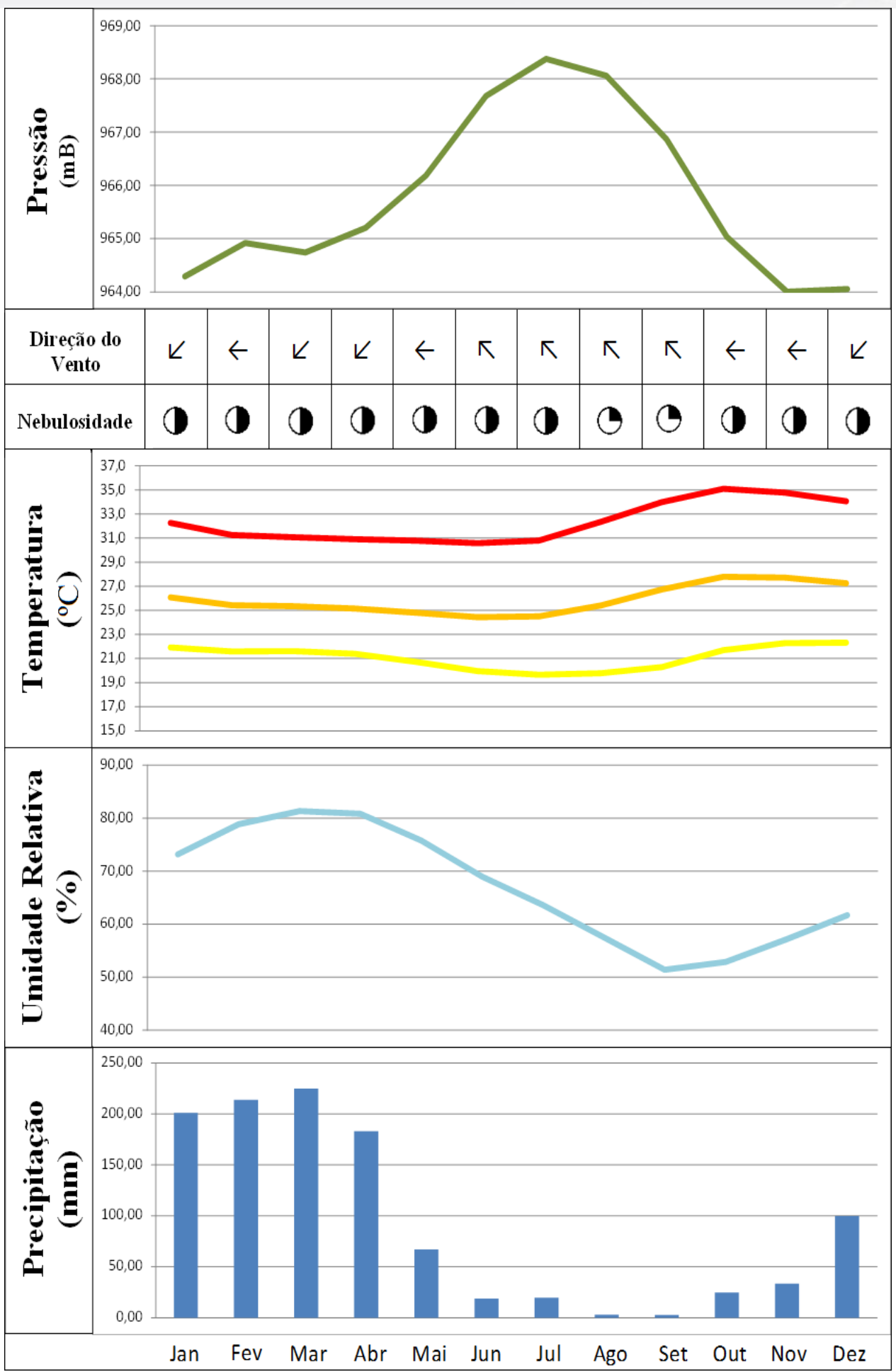

Figura 2 - Gráfico de elementos climáticos segundo dados da estação meteorológica de Barbalha-CE no período de 1983 a 2013

Fonte: INMET (2016).

A distribuição espacial das chuvas está ligada à posição dos postos em relação à Chapada do Araripe. A 


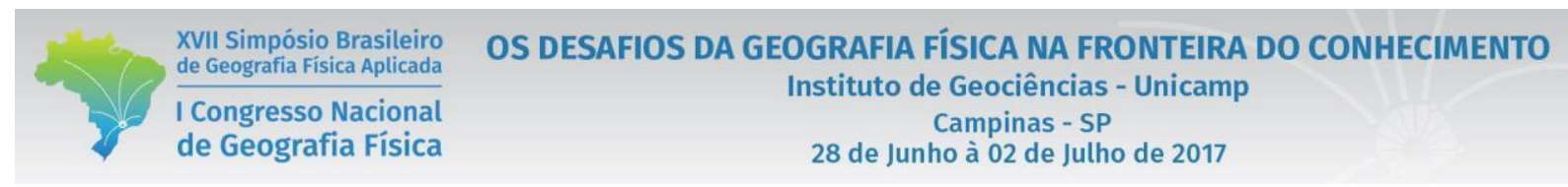

cidade do Crato se encontra na vertente norte (barlavento), recebendo ventos úmidos que causam maior precipitação ao encontrar a barreira orográfica (média anual de 1142mm). Jardim está a sudoeste (sotavento), e apresenta os menores valores pluviométricos entre as 4 cidades estudadas (776mm). Milagres e Brejo Santo estão a leste da chapada, registrando valores de precipitação mensal e anual muito próximos, uma vez que são as cidades que menos recebem influência da chapada (Figura 3 a/b; Tabela 1).

Verifica-se no gráfico de médias mensais (Figura 3.b) que as estações seca e chuvosa são bem definidas. A estação chuvosa ocorre entre janeiro e abril, com valores acima de 100mm devido à influência da Zona de Convergência Intertropical (ZCIT). Na estação seca são encontrados valores entre 2,9mm e 40mm, relacionando-se a atuação do Anticiclone Subtropical do Atlântico Sul (ASAS) de junho a novembro.

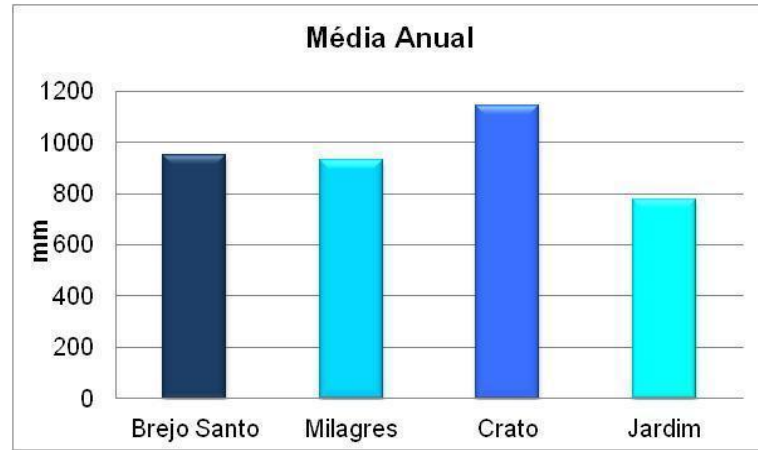

(a)

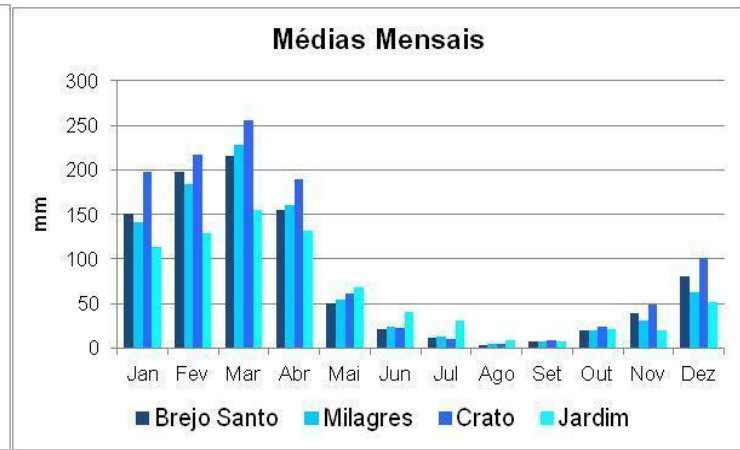

(b)

Figura 3 - (a) Gráfico que compara a média anual de cada cidade. (b) Gráfico que mostra as médias mensais e a sazonalidade das chuvas marcando a estação seca (junho a novembro) e a chuvosa (janeiro a abril). Maio e dezembro são considerados meses de transição. Fonte dos dados: Agência Nacional de Águas (ANA)

Tabela 1 - Comparação dos valores médios da pluviosidade mensal e anual (mm) das cidade.

\begin{tabular}{lcccc}
\multicolumn{5}{c}{ Médias Mensais e Anual (mm) } \\
\hline & $\begin{array}{l}\text { Brejo } \\
\text { Santo }\end{array}$ & Milagres & Crato & Jardim \\
\hline Jan & 150,4 & 140,8 & 198,1 & 113,1 \\
Fev & 197,9 & 184,4 & 217,3 & 128,9 \\
Mar & 215,8 & 227,4 & 256,3 & 154,9 \\
Abr & 155,6 & 160,6 & 189,2 & 131,7 \\
Mai & 49,9 & 54,5 & 61,8 & 68,3 \\
Jun & 21,7 & 24,2 & 22,9 & 40,6 \\
Jul & 12,1 & 12,4 & 10,1 & 30,3 \\
Ago & 2,9 & 4,9 & 4,3 & 8,5 \\
Set & 7,5 & 7,9 & 8,7 & 7,0 \\
Out & 19,5 & 20,6 & 24,4 & 21,1 \\
Nov & 39,1 & 30,9 & 48,5 & 20,1 \\
Dez & 79,9 & 63,0 & 100,9 & 51,6 \\
\hline
\end{tabular}




\begin{tabular}{lrrrr}
\hline ANUAL & 952,3 & 931,7 & 1142,4 & 776,1 \\
\hline
\end{tabular}

A migração da ZCIT entre os hemisférios norte e sul no oceano Atlântico é norteada pela termodinâmica global, na qual o deslocamento das células de pressão na circulação geral da atmosfera tem sua variação sazonal determinada pelos invernos, tanto no hemisfério norte quanto no hemisfério sul. No inverno até o início da primavera do hemisfério norte, a ZCIT tende a se deslocar latitudinalmente a sul, cobrindo a parte equatorial continental do hemisfério sul,produzindo as chuvas do NEB. O inverso ocorre quando do período de inverno no hemisfério sul (CAVALCANTI, et al. 2009). Tal dinâmica, que produz a variabilidade da TSM, também modula os demais sistemas atmosféricos e centros de ação, influenciando os deslocamentos do Anticiclone Subtropical do Atlântico Sul (ASAS) e do Anticiclone Subtropical do Atlântico Norte (ASAN). Longitudinalmente, essas altas deslocam-se pelo oceano, podendo estabilizar-se por um período. No caso do ASAS, essa estagnação pode ocorrer sobre o continente sul-americano durante o inverno austral. Ao deslocar-se para leste, o ASAS acaba por enfraquecer a atuação dos alísios sobre NEB, já em seu deslocamento para oeste, acaba por fortalecer os alísios (DEGOLA, 2013).

Nota-se que, na maior parte do ano, a cidade do Crato possui valores mensais de chuva acima das outras cidades (de $28 \mathrm{~mm}$ a $101 \mathrm{~mm}$ em março), o que é fruto de sua posição geográfica a barlavento da Chapada do Araripe. Em contraposição, Jardim, a cidade com menores valores pluviométricos, possui médias mensais de chuva até 2 vezes maior que as outras cidades durante a estação seca $(40,6 \mathrm{~mm}, 30,3 \mathrm{~mm}$ e 8,5 $\mathrm{mm}$ em junho, julho e agosto), caracterizando uma curva menos acentuada na variabilidade intrassazonal da precipitação, com menores amplitudes médias ao longo do ano. Isso pode ser fruto da influência de Sistemas Frontais (SF), que, durante o inverno ganham força e chegam a alcançar o sul do Ceará, podendo até ultrapassar a linha do equador (NIMER, 1989; MENDONÇA e DANNI-OLIVEIRA, 2007).

Nimer (1989) dedicou um capítulo de seu livro exclusivamente à Região do Cariri Cearense, mais especificamente às cidades de Farias Brito, Caririaçu e Jati, considerando a série histórica de 1934 a 1957. $\mathrm{O}$ autor identificou as estações secas e chuvosas muito bem delimitadas, os meses de fevereiro, março e abril como os mais chuvosos e expôs a questão da irregularidade das chuvas como o real problema da região NEB. No entanto, ao considerar uma série histórica de apenas 23 anos, o Nimer (op cit.) não consegue definir padrões de variabilidade, ainda que o autor tenha destacado, na época, que anos de chuva concentrada no Cariri Cearense antecedem secas de duração e intensidade com variabilidade excepcional. Nessa esteira, ao ser considerada uma série histórica maior, - como neste estudo -, são observados ciclos de oscilação positiva e negativa.

Os totais pluviométricos entre os postos normalmente seguem a mesma tendência nas variações acima e 
abaixo da média, como é demonstrado na Figura 4. Anos em que um posto registra médias muito diferentes dos outros, como 1960 ou 1977, podem ser colocados como excepcionais. Crato, apesar de chover em média mais de $100 \mathrm{~mm}$ (março) que Jardim, não mantém a mesma tendência ao observarmos o desvio pluviométrico na Figura 4. Da mesma forma, observa-se que Brejo Santo e Milagres, apesar da proximidade geográfica e se encontrarem a leste da chapada, acabam apresentando valores significativamente distintos. Isto pode ser decorrente da diferença de altitude entre as cidades e da atuação de diferentes sistemas produtores de chuva sobre a região.

No que tange à análise temporal, as décadas de 1980 e 1990 apresentam extremos, tanto de anos chuvosos quanto de anos secos, ultrapassando os $1000 \mathrm{~mm}$ em 1985 e com um déficit de quase $600 \mathrm{~mm}$ em 1993 . As décadas de 1960 e 1970, apesar dos valores em geral acima da média, apresentam valores mais "harmônicos" se comparados às outras décadas. Já o final da década de 1990 e os anos 2000 aparentemente possuem o gráfico com a curva mais suave, ou seja, com menor amplitude entre os desvios positivos e negativos. Porém, ao mesmo tempo em que encontramos valores acima da média em algumas cidades, em outras as chuvas foram significativamente abaixo ou muito próximas da média.

As teleconexões participam de forma significativa na modulação das chuvas, sobretudo em escala interanual e interdecenal. O que foi observado no gráfico (Figura 5) é a sua influência sobre a frequência pluviométrica no NEB. Isto ocorre devido às mudanças da TSM no oceano Pacífico, causadas pelo ENOS e ODP, que modificam também a TSM no oceano Atlântico. Essa dinâmica termo-barométrica conduz a ZCIT em seu máximo para sul em anos de La Niña. Em anos de El Niño, a ZCIT não chega a alcançar sua posição meridional máxima. Uma segunda razão pode ser pela alteração na $\mathrm{CW}$, que fortalece seu ramo descendente sobre o NEB em anos de El Niño e enfraquece em anos de La Niña.

Os os valores das pluviosidades, de um modo geral, são inversamente proporcionais aos valores de ENOS e ODP.Verifica-se a relação inversamente proporcional da pluviosidade e das fases do ENOS e ODP nos valores percentis apresentados no gráfico de CHA (Figura 5). No ano de 1964, considerado de La Niña moderada pelo CPTEC/INPE, ENOS e ODP trazem o valor de $-0,8 \%$, enquanto as cidades possuem chuva de $0,3 \%$ a 2,3\%. O ano de 1969 , de El Niño moderado com valor de $0,5 \%$, a ODP foi $-0,1 \%$, valor elevado para uma fase negativa, e por conta dessa combinação encontra-se os valores pluviométricos negavivos de $-0,4 \%$ a $-1,1 \%$. Em 1985 a La Niña apresentou o valor de -0,4\%, a ODP foi 0,5\%, e as chuvas foram de 2,3\% a 3,5\% acima da média, valores extremamente altos. Já 1993, o ENOS foi 1,1\% e a ODP 1,4\% acima da média, em contraposição os valores pluviométricos foram de $-1,2 \%$ a $-2,1 \%$, tornando 1993 o ano mais seco da série histórica estudada. 


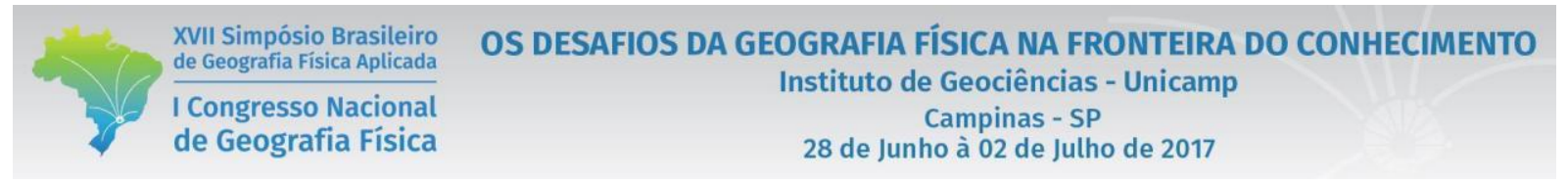




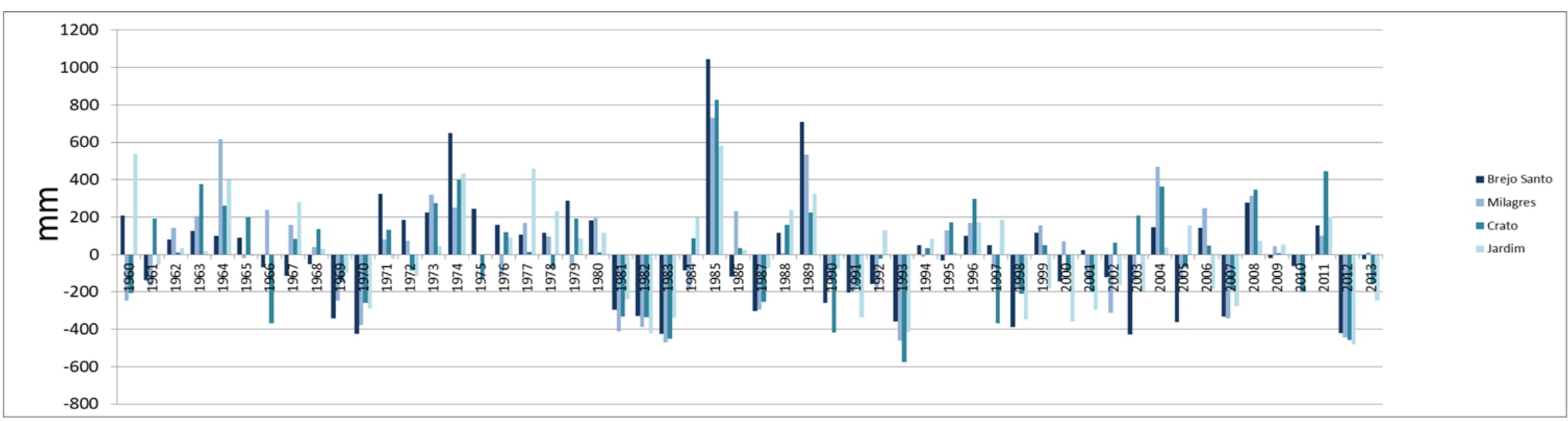

Figura 4 - Gráfico representando os desvios pluviométricos acima (positivos) e abaixo (negativos) da média na região durante a série histórica de 1960 a 2013. Fonte dos dados: ANA (2014)

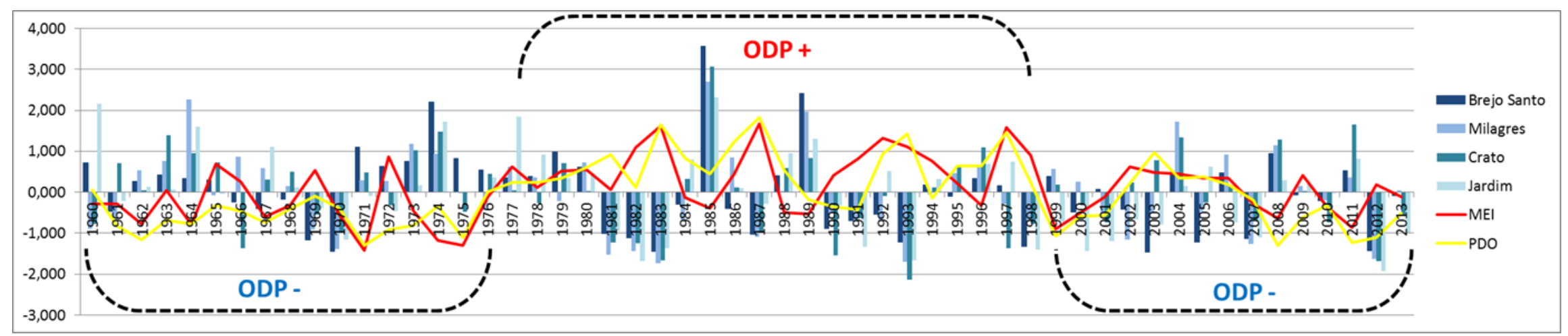

Figura 5 - Chuva Acumulada Anual (CHA) por posto pluviométrico (barras) associados ao MEI - Índice Multivariado ENOS (linha vermelha) e ao PDO - índice da ODP (linha amarela).

Fonte dos dados: ANA (2014), ESRL/NOAA (2016) e University of Washington (2016). 
Pode-se considerar que a ODP atua na modulação dos totais pluviométricos decenais. A fase positiva da ODP (de 1977 a 1998) apresenta os maiores totais positivos e negativos da série histórica estudada, o que quer dizer que tanto os anos mais chuvosos, quanto os anos de seca extrema estão concentrados na fase quente. A primeira fase fria da ODP considerada do presente artigo (de 1960 a 1976) apresenta totais pluviométricos, em sua maior parte, positivos. Há anos com desconformidade entre os valores comparados de cada cidade. Isso pode ser fruto da flutuação discrepante do ENOS em relação a ODP, com anos de El Niño moderados, de acordo com as tabelas apresentadas no site do CPTEC/INPE. Já a segunda fase fria apresentada no gráfico (de 1999 a 2013), constitui-se como uma fase recente. Apesar de constar na literatura que a nova fase teve início entre 1998 e 1999, observa-se a flutuação positiva da ODP entre os anos de 2002 a 2006, acompanhada de sucessivos El Niños. Novamente são apresentadas desconformidades entre os valores pluviométricos das cidades, assim como os valores mais próximos da média, em comparação a fase quente. Como foi discutido, a diferença da precipitação entre as cidades é resultado dos fatores geográficos do clima que caracterizam a área, uma vez que se tratam de cidades muito próximas. Possivelmente a diferença entre tais valores apresentados no gráfico de CHA (Figura 5) ocorre pelo fortalecimento de outros sistemas produtores de chuva, como os Sistemas Frontais, que favorecem chuvas nas cidades ao sul da chapada.

\section{Conclusão}

Visivelmente há ciclos bem definidos na variabilidade da pluviosidade da Região do Cariri Cearense. Considerando que a dinâmica atmosférica está ligada a uma gama variada e numerosa de fatores, sabe-se que a variabilidade temporal e espacial dos totais pluviométricos não são dependentes exclusivamente dos fenômenos ENOS e ODP. Porém, pode-se notar a importância de tais fenômenos para determinar anos secos ou chuvosos na área de estudo, funcionando de forma inversamente proporcional. Este fato é marcadamente temporal, pois os maiores totais decenais de chuva estão associados à disposição dos padrões de variabilidade no tempo, e não necessariamente à magnitude da precipitação. Entretanto, o inverso pode sim ter interdependência, ou seja, a magnitude pluviométrica pode estar conectada à ocorrência de fases positivas ou negativas da ODP e ENOS. Para a comprovação das observações, os próximos passos da pesquisa se darão na aplicação de técnicas estatísticas. 


\section{Bibliografia}

AB'SABER, A. N. Os domínios de natureza no Brasil: potencialidades paisagísticas. São Paulo: Ateliê Editorial, 2003, p. 160.

ANA, Sistema Nacional de Informações sobre Recursos Hídricos. Disponível em: <http://www.snirh.gov.br/hidroweb/> Acesso em: set. 2014.

BARROS, J. R.; ZAVATTINI, J. A. Bases Conceituais em Climatologia Geográfica. Mercator(Fortaleza. Online), v. 8, p. 255-261, 2009.

CAVAlCANTI, I. F. A. et al. (Orgs) Tempo e Clima no Brasil. São Paulo: Oficina de Textos, 2009. 463 p.

CPTEC/INPE. ENOS. jul. 2016. Disponível em: 〈http://enos.cptec.inpe.br/\#> Acesso em: 12 jul. 2016.

DEGOLA, T. S. D. Impactos e variabilidade do Anticiclone Subtropical do Atlântico Sul sobre o Brasil no clima presente e em cenários futuros. 2013. 112 f. Dissertação (Mestrado em Meteorologia) - Instituto de Astronomia, Geofísica e Ciências Atmosféricas, Universidade de São Paulo, São Paulo. 2013. Disponível em: $<$ http://www.iag.usp.br/pos/sites/default/files/d thiago_s_d_degola_corrigida.pdf $>$ Acesso em: 03 jul. 2016.

ESRL/NOAA, Multivariate ENSO Index. Physical Science Division. 2016. Disponível em: <http://www.esrl.noaa.gov/psd/enso/mei/> Acesso em: 17 jun. 2016.

Governo do Estado do Ceará. Secretaria de Recursos Hídricos. Sistema de Informação dos Recursos Hídricos do Ceará. Atlas do Estado do Ceará, 2008. Disponível em: 〈http://atlas.srh.ce.gov.br/> Acesso em: 10 jul. 2016.

IAG/USP, Climatologia Dinâmica do Brasil e principais sistemas meteorológicos, 2016. Disponível em: <http://master.iag.usp.br/pr/ensino/sinotica/aula04/> Acesso em: 04 ago. 2016.

IBGE, Departamento de Cartografia, Mapa de Clima do Brasil. Adaptado IBGE 1978. [Rio de Janeiro], 2002. Escala: 1:5000 000 .

INMET, Banco de Dados Meteorológicos para Ensino e Pesquisa. Disponível em: $<$ http://www.inmet.gov.br/projetos/rede/pesquisa/> Acesso em: 19 jun. 2016.

MANTUA, N. J.; HARE, S. R. The Pacific Decadal Oscillation. Journal of Oceanography, v. 58, n. 1, p. 35-44, 2002.

MENDONÇA, F.; DANNI-OLIVEIRA, I. M. Climatologia: noções básicas e climas do Brasil. São Paulo: Oficina de Textos, 2007. $206 \mathrm{p}$.

MOLION, L. C. B. Aquecimento global, El Niños, manchas solares, vulcões e Oscilação Decadal do Pacífico. Climanalise, CPTEC/INPE, 2005.

NIMER, E. Climatologia do Brasil. $2^{\text {a }}$ ed. Rio de Janeiro: IBGE, Departamento de Recursos Naturais e Estudos Ambientais, 1989. 422 p.

SIQUEIRA, A. H. B, et al. Impactos do ENOS no Norte e Nordeste Brasileiros e sua relação com a Oscilação Decadal do Pacífico. In: Anais do XIV Congresso Brasileiro de Meteorologia, SBMET. Vol. 26. 2006.

UNIVERSITY OF WASHINGTON, Pacific Decadal Oscillation. Joint Institute for the Study of the Atmosphere and Ocean. 2016. Disponível em: 〈http://research.jisao.washington.edu/pdo/PDO.latest〉 Acesso em: 21 jun. 2016. 